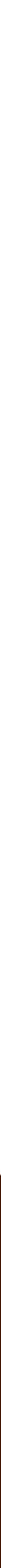


Министерство образования и науки Российской Федерации КУБАНСКИЙ ГОСУДАРСТВЕННЫЙ УНИВЕРСИТЕТ

\section{АКТУАЛЬНЫЕ ВОПРОСЫ СОВРЕМЕННОЙ ФИНАНСОВОЙ НАУКИ}

Материалы заочной всероссийской научно-практической конференции 
Пенюгалова А.В. (ответственный редактор)

Сысоева ЕФ.

Пригода Л.В.

Буз О.В.

Цициашвили С.С.

Ермоленко О.М.

Мамий Е.А.

Гребенникова В.А.

Федотова Е.Б.

Тюфанов B.A.

\section{Редакиионная коллегия:}

доктор экономических наук, профессор заведующий кафедрой экономического анализа, статистики и финансов ФГБОУ ВО «Кубанский государственный университет»

доктор экономических наук, профессор заведуюший кафедрой «Финансы и кредит» ФГБОУ ВО «Воронежский государственный университет»

доктор экономических наук, профессор заведуюший кафедрой «Финансы и кредит» ФГБОУ ВО «Майкопский государственный технологический университет» кандидат экономических наук генеральный директор ООО «Печатный двор Кубани» кандидат экономических наук начальник отдела Управления рисками, кредитного контроля и комплаенса

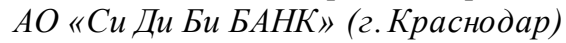

кандидат экономических наук, доцент доиент кафедры экономического анализа, статистики и финансов ФГБОУ ВО «Кубанский государственный университет»

кандидат экономических наук, доиент заместитель заведующего кафедрой экономического анализа, статистики и финансов по учебно-методической работе

ФГБОУ ВО «Кубанский государственный университет»

кандидат экономических наук, доиент

дочент кафедры экономического анализа, статистики и финансов

ФГБОУ ВО «Кубанский государственный университет»

кандидат экономических наук, дочент

доцент кафедры экономического анализа, статистики и финансов ФГБОУ ВО «Кубанский государственный университет»

кандидат экономических наук преподаватель кафедры экономического анализа, статистики и финансов ФГБОУ ВО «Кубанский государственный университет»

Актуальные вопросы современной финансовой науки [Электронный ресурс] : материалы заочной всероссийской научно-практической конференции (28 февраля 2017 г., Краснодар) / под ред. А. В. Пенюгаловой. - Краснодар: КубГУ, Майкоп: ЭлИТ, 2017. 567 с.: - Режим доступа http://201824.selcdn.ru/elit-036/index.html. Дата размещения 28.02.2017 г.

ISBN 978-5-9909192-6-6. doi: 10.18411/elit-036.

В сборник вошли статьи, представленные на Всероссийскую заочную научно-практическую конференцию «Актуальные вопросы современной финансовой науки». Сборник охватывает широкий круг актуальных проблем в области финансов, денежно-кредитной сферы, финансовых рынков, макро- и микроэкономики. Показаны современное состояние, пути и направления дальнейшего развития финансово-кредитной науки и практики. Сборник статей может быть рекомендован специалистам в области финансов и кредита, научным работникам, преподавателям вузов, студентам, аспирантам, магистрантам.

\section{Редакционная коллегия не несет ответственности за содержание публикуемых материалов. \\ Материалы публикуются в авторской редакции.}
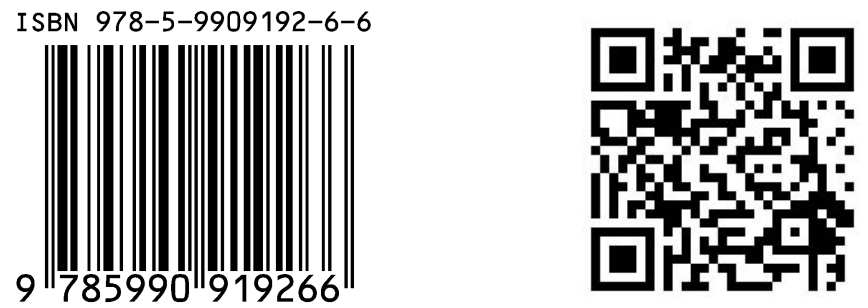

(C) ФГБОУ ВО «КубГУ», 2017

(C) Коллектив авторов, 2017

(C) Оформление электронного издания ООО «ЭлИТ», 2017 


\section{ОГЛАВЛЕНИЕ}

РАЗДЕЛ І. ФИНАНСЫ

Абасова Д. Р., Гребенникова В.А.

Международное двойное налогообложение и способы его урегулирования

Авжиян К.P., Бергаль Е.В.

Государственная финансовая поддержка предприятий малого бизнеса

Авжиян К.Р., Вылегжанина Е.В.

Анализ управления формированием и оборотом финансовых ресурсов

промышленных предприятий Краснодарского края.....

Александрова Л.И., Федотова Е.Б.

Понятие, сущность и значение финансовых результатов предприятия

Алиев T.С., Тимченко Е.В.

Сущность и особенности классификации инвестиционных рисков проектов

в современных условиях

Байрамова Д.Д., Байдикова К.А, БергальЕ.В.

Региональные аспекты развития финансовой инфраструктуры поддержки малого

и среднего бизнеса

Белоусова А.С., Мамий Е.А.

Роль оценки инвестиционных проектов в процессе достижения эффрективности

инвестиционной политики нефтегазового предприятия

Бизаева М.А., Вылегжанина Е.В.

Управление финансовыми ресурсами

промышленных предприятий

Богданович А.Н, Федотова Е.Б.

Современное состояния платежной дисциплины

хозяйствующих субъектов .

Богданович А.Н, Федотова Е.Б.

Финансовые расчеты хозяйствующего субъекта в условиях дефицита денежных средств

с учетом налоговых последствий.

Бойко А.П., Вылегжанина Е.В.

Практика управления рисками продовольственного предприятия

Бондарева А.Н., Гребенникова В.А.

Модернизация имущественного налогообложения физических лиц в России.

Бочарова А.И., Мамий Е.А.

Проблемы оченки эфррективности инвестиционных проектов в современных условиях

Васильев А. А., Сайбель Н.Ю.

Создание ценного предложения для улучшения результатов продаж

и повышения доходов предприятия

Володина Е.M.

Оценка проблемных активов.

ГельвидесО. С., ФедотоваЕ. Б.

Финансовое моделирование экономического роста компании..

Грабко Д.В. , Вылегжанина Е.В.

Мониторинг платежеспособности и финансовой устойчивости российских компаний.

Гребенникова В.А., Зуенко Е.В.

Преимущества и риски патентной системы налогообложения 
Гребенникова В.А., Нейфрельд А.А.

Налоговые льготы для пенсионеров и их социальное значение в современной России.

Гребенникова В.А., Пицина А.П.

Мировая практика применения специальных режимов налогообложения.

Гребенникова В.А., Потюпенко А.А.

Транспортный налог и его роль в формировании дорожных фондов.

Демьяненко Д.А., Платонова Ю.Ю.

Особенности регулирования финансового сектора экономики

Диголян К.С., Базилевич А.Р.

Обоснование причин инфляции в современных условиях РФ

Журавлева Н.А.

Финансовое управление на предприятии в условиях кризиса в России и за рубежом.

Заика В. В., Вылегжанина Е. В.

Управление себестоимостью и эфрфективностью производства.

Зимарев Л.А., Вылегжанина Е.В.

Модификация EOQ-модели для определения потребности в запасах

Иванова А.Ю., Кирокосян М.А.

Ключевые параметры оценки финансовой состоятельности предприятия.

КалашниковаА. И., Вылегжанина Е.В.

Оценка и управление деловой активностью промышленных предприятий в краснодарском крае ..... 125

Карачкова Е.А., Вылегжанина Е.В.

Оценка эффективности государственнойподдержки малого бизнеса в Краснодарском крае:

финансовый аспект

Ларина М.С., Гребенникова В.А.

Реформирование налоговой системы РФ

Лембурова В.М.

Инвестиционная привлекательность краснодарского края.

ЛитвиноваМ.А.

Проблемы реформирования пенсионной системы в современной России.

Мазницкая Ю.В. , Вылегжанина Е.В.

Формирование оптимальной финансовой структуры капитала в кризисной экономике

Макаренко А.С., Платонова Ю.Ю.

Особенности таргетирования инфляяии в условиях неопределённости экономической ситуации ... 149

Макоева Д.Р., Гребенникова В.А.

Перспективы модернизации НДФЛ с учетом зарубежной практики подоходного налогообложения. 153

Мамий М.B., Мамий Е.A.

Методы оценки рисков проекта при проектном финансировании ....

Маслий И. В., Вылегжанина Е. В.

Формирование и оборот финансовых ресурсовмалых промышленных предприятий

Краснодарского края ...

Мешвез Д. Ю., Вылегжанина Е.В.

Особенности финансов хозяйственных партнерств.

МорозА.Н., Вылегжанина Е.В.

Проблемы доступа малого бизнеса к финансовым ресурсам (на примере Краснодарского края) ......... 170

Павленко С.А., Гребенникова В.А.

ЕСХН как инструмент развития агропромышленного комплекса Кубани.

Панеш 3. А., Федотова Е.Б.

Оценка стоимости предприятия в системе финансового менеджента 
Петелина Я.П., Тимченко Е.В.

Развитие инвестиционной деятельности пенсионного фонда России 184

Петрова Т.А., Гребенникова В. А.

НДФЛ: сочиальная роль и значение в формировании бюджетных доходов Краснодарского края

Петровская А. О., Федотова Е.Б.

Методы прогнозирования финансовых показателей

Рудаков К.В., Мамий Е.А.

Реализация инфраструктурных и социальных проектов в Краснодарском крае:

предпосылки и перспективы..

Руденко Я.И., ВылегжанинаЕ.В.

Формирование инвестиционной стратегии предприятия.

Садовникова И.В., Федотова Е.Б.

Инвестиционная привлекательность предприятия в современных условиях

Сергин И.Д., Вылегжанина Е.В.,

Финансовые проблемы предприятий среднего и малого бизнеса в современных условиях

Сорокина А.М., Бергаль Е.В.

Налоговый контроль как фактор повышения экономической безопасности региона

Сорокина А.М., Вылегжанина Е.В.

Особенности финансов коммерческих компаний строительной отрасли

Сушко В.В., Вылегжанина Е.В.

Налоговый механизм стимулирования инвестиций.

Таков Р.М., Вылегжанина Е.В.

Финансовые аспекты развития виноградарства в Краснодарском крае.

Трегубенко В.М., Вылегжанина Е.В.

Подходы к формированию собственного капитала.

Удалова Э.В., Мамий Е.А.

Проблемы франчайзинга в России.

Ункурова А. Ч., Федотова Е.Б.

Особенности привлечения инвестиций в гостиничный бизнес.

Усток С. Н., Федотова Е.Б.

Современные аспекты формирования и распределения прибыли.

Федина А. А., Вылегжанина Е.В.

Управление дебиторской задолженностью в период кризиса

Фирсакова А.И., ГребенниковаВ.А.

Прогрессивное подоходное налогообложение физических лиц и его роль

в справедливом распределении доходов.

Ханабеева Т.В., Вылегжанина Е.В.

Инструменты налогового стимулирования инвестиционного процесса на региональном уровне..... 252

ХуадеА.Ш., Федотова Е.Б.

Категория финансовой устойчивости как критерий конкурентоспособности

розничных торговых сетей

Хуако 3. А., Пенюгалова А.В.

Сущность и факторы финансовой устойчивости в современных условиях

Церюпа Е.А., Вылегжанина Е.В.

Повышение деловой активности на основе создания промышленных парков в Краснодарском крае . 264

Чуксина Д.В., Гребенникова В.А.

Эволючия страховых сочиальных взносов в Российской Федерации.. 
Чулков А.С., Наталенко К.В.

Пути повышения качества государственных и муниципальных услуг

Шадбекова И. Ф., Гребенникова В. А.

Современное состояние лизинговых операций в России и краснодарском крае

ШацкихЮ.В., Вылегжанина Е.В.

Идентификация проблем привлечения финансовых ресурсов в малом бизнесе.

Шmода A.Н., Федотова Е.Б.

Анализ трактования инвестиционной привлекательности компаний российского рынка

продуктового ритейла.

Шумилова А.С., Гребенникова В.А.

Вектор развития вменённого налогообложения в современной России

Якименко Ю.В., Вылегжанина Е.В.

Финансовая стабилизация предприятия на основе реорганизации ...

РАЗДЕЛ ІІ. ДЕНЬГИ, КРЕДИТ, БАНКИ

Агрба Д.Л., БазилевичА.Р.

Особенности продвижения новых банковских продуктов

Айрапетян Л. Л., БазилевичА. Р.

Оценка проведения кредитной политики ЦБРФ на современном этапе

Амбариумян К.А., Ермоленко О.М.

Теоретический подход к определению структуры золотовалютных резервов России

Базилевич А.Р., Дашдамирова Ф.Э., Карайчинцева Е.А.

Роль кредитного департамента в процессе управления ликвидностью банка

Базилевич А.Р., КобжМ.М.

Развитие и организация потребительского кредитования в коммерческом банке

Базилевич А.Р., Сорокина Е.И.

Проблемы управления кредитными рисками в сфере ипотечного кредитования и пути их решения 316

Баум Г.А., ПлатоноваЮ.Ю.

Тенденции развития риск-менеджмента в коммерческих банках: зарубежная практика

Бочарова А.И., Платонова Ю.Ю.

Актуальные вопросы развития национального банковского сектора

Виноградова К.Е., Мамий Е.A.

Оценка и направления совершенствования политики Центрального Банка

Гребенникова В.А., Деревщикова Е.О.

Проблемы и пути совершенствования налогообложения прибыли банков.

Дашдамирова Ф.Э., Базилевич А.Р.

К вопросу о ликвидности коммерческого банка

Джигкаев А.Р. , Казанский А.А., Базилевич А.Р.

Разработка банковского продукта

Дурнева Э. С., Платонова Ю.Ю.

Современные методические подходы коценке конкурентоспособности

банковской системы России.

Дурнева Э. С., Платонова Ю.Ю.

Некоторые особенности банковской конкуренции в России

Епраносян А.А., Базилевич А.Р.

Влияние новых кредитных продуктов наэффрективность деятельности коммерческого банка.... 351 
Епраносян А.А., Вылегжанина Е.В.

Особенности отношения населения 2. Краснодара к кредиту как социальному явлению 356

Ешева С.К., Ермоленко О.М.

Современные тенденции изменения кредитного риска в банковском секторе России 361

Зайков В.П.

Проблемы налогообложения и формирование финансового результата кредитных организаций .... 365

Зайцев М. Н., ФедотоваЕ. Б.

Финансовое планирование в коммерческих предприятиях (организациях)

Зайцев М. Н., Федотова Е. Б.

Финансовое планирование в коммерческих организациях как первоисточник бюджетирования

Кеосиди И.И., Власова С.Е., Ермоленко О.М.

Теоретические аспекты сущности рынка евровалют в современной экономике

Котляр Е.А., Галяева Л.Е.

Тенденции кредитного риска в региональных банках в условиях нестабильной экономики

Котляр Е.С., Мамий Е.A.

Пути повышения эффективности надзорной функции и реформирования

Центрального Банка России

Кузьменко Д. Ю, Ермоленко О.М.

Возможности перехода преимущественно на безналичные формы расчетов.

Макаренко А.С., Базилевич А.P.

Современные технологии дистанционного банковского обслуживания

Макаренко А.С., Вылегжанина Е.В.

Кредитные риски: особенности возникновения и подходы к регулированию

Макоева Д.Р., Базилевич А.Р.

Антикризисные меры и механизм работы с проблемными банками

Нейфельд А. А., БазилевичА.Р.

Состояние государственного долга современной России

Папик T.T., БазилевичА.P.

Оченка эфррективности деятельности коммерческого банка в рыночной экономике

ПарпулаИ.И.

Расчетные банковские инструменты в антикризисном проектном финансировании

ПетровА.Е., Ермоленко О.М.

Банковские услуги в деятельности банков: тенденции и перспективы

Пилаев В.М., Базилевич А.P.

Влияние фальшивомонетничества на макроэкономическое развитие в российской фредерации

Платонова Ю. Ю., Пономарева А. Ю.

Характеристика институциональной структуры региональной банковской системы

ПлатоноваЮ.Ю., СмоляковаН.В.

Актуальные проблемы денежно-кредитного регулирования российской экономики

Платонова Ю.Ю., Терехова А.А.

Инфляционное таргетирование как режим денежно-кредитной политики в РФ

Пригода Л. В., Трофименко М.В.

Анализ основных проблем в срере кредитования физических лиц в России и пути их решения

Рябовол Е.А., Базилевич А.Р.

Особенности инвестиционного кредитования сельскохозяйственных производителей 
Турашов И.В., Ермоленко О.М.

Роль банковских инноваций в развитии банковского сектора

Фролова Т.Д., Базилевич А.Р.

Предпосылки и тенденции слияния и поглощения в современном российском банковском секторе ... 452

Хачатрян В.Г., БазилевичА.Р.

Особенности кредитования агропромышленных предприятий

Шадбекова И. Ф., БазилевичА. Р.

Особенности разработки новых банковских продуктов

Щербина А.О., Базилевич А.Р.

Направления регулирования и надзора за банковской деятельностью в период нестабильного развития экономики

РАЗДЕЛ ІІІ. ФИНАНСОВЫЕ РЫНКИ.

Алиева С. В., Гудакова Л.В.

Особенности взаимодействия элементов инфраструктуры рынка ценных бумаг в России.....

Знаменская А. А., Вылегжанина Е. В.

Виды дивидендных политик компании

КанапацкаяЕ.Н., Вылегжанина Е.В.

Идентирикация факторов, определяющих развитие рынка недвижимости

Кочубей E. О., Федотова Е.Б.

Типы дивидендной политики акционерного общества

МорозовМ.И., Тимченко А.И.

Происхождение фундаментального и технического анализа как основных

методов прогнозирования цен на финансовом рынке.

Никонов К.М., Гудакова Л.в.

Анализ рынка производных финансовых инструментов на современном этапе

Пучкина Е.С., ОвчинниковВ.Б.

Сущность и подходы к определению облигации

РАЗДЕЛ IV. МАКРО- И МИКРОЭКОНОМИКА

Байдикова К.А., Вылегжанина Е.В.

Организация бизнеса через офрфшорные юрисдикции.

Байрамова Д.Д., Вылегжанина Е.В.

Проблемы малого бизнеса в Краснодарском крае.

Васильев А. А., Федотова Е.Б.

Возможности ассоциативных связей и правил в принятии эфрфективных решений бизнеса 504

Величко Е. А., Федотова Е.Б.

Современные элементы бизнес-среды и инструменты управления предприятием.

Волошина Д.О., Вылегжанина Е.В.

Особые экономические зоны и их влияние на экономику России

ГельвидесО. С., ФедотоваЕ. Б.

Модели устойчивого экономического роста компании

Григорян А.И., Вылегжанина Е.В.

Управление деловой активностью промышленного комплекса Краснодарского края

Колодько Д.А., Вылегжанина Е.В.

Классификация офршиорных зон и схемы оффршорного бизнеса

Лях А.А., Вылегжанина Е.В.

Деловая активность промышленных предприятий в Краснодарском крае 
Пивоваров Д.А., Вылегжанина Е.В.

Теоретические и методические основы управления рисками

Пригода Л.В., Ахметов З.Э.

Современные тенденции демографического развития общества: вызовы и решения

Ромахова Е.Н., Вылегжанина Е.В.

Реорганизация как метод стабилизации финансового состояния предприятия

Рудченко А.М., Ермоленко О.М.

Улучшение социально- экономическогоположения моногородов России путём развития

в них малого предпринимательства

Стовбун В.В., Базилевич А.P.

Концептуальный подход к определению финансовой инфраструктуры России

Тимченко Е.В., Вылегжанина Е.В.

Коррупция как фактор угрозы экономической безопасности

Христенко А.Б., ГребенниковаВ.А.

Оптимизация налоговой нагрузки на макроуровне в целях стимулирования

предпринимательской активности в РФ

Ширшов С.К, Ермоленко О.М.

Современные проблемы развития малого бизнеса в краснодарском крае 